\title{
Analysis of the effect of external heating in the human tissue: A finite element approach

\author{
Mridul SANNYAL ${ }^{\mathrm{a},{ }^{*},}$, Abul Mukid Mohammad MUKAdDES ${ }^{a}$, Md. Matiar RAHMAN ${ }^{b}$, M. A. H. Mithu ${ }^{a}$ \\ ${ }^{a}$ Department of Industrial and Production Engineering, Shahjalal University of Science and Technology, Sylhet, Bangladesh \\ ${ }^{b}$ Department of Mathematics, Shahjalal University of Science and Technology, Sylhet, Bangladesh \\ *E-mail address: sannyalmridul@gmail.com
}

\begin{abstract}
Thermal therapy which involves either raising or lowering tissue temperature to treat malignant cells needs precise acknowledgment of thermal history inside the biological system to ensure effective treatment. For this purpose, this study presents a two-dimensional unsteady finite element model (FEM) of the bioheat transfer problem based on Pennes bio-heat equation to analyze the thermal response of tissue subject to external heating. Crank-Nikolson scheme was used for the unsteady solution. A finite element code was developed using $\mathrm{C}$ language to calculate results. The obtained numerical result was compared with the analytical and other numerical results available in the literature. A good agreement was found from the comparison. Temperature distribution inside the human body due to constant and sinusoidal spatial and surface heating were analyzed. Response to point heating was also investigated. Moreover, a sensitivity analysis was carried out to know the effect of various parameters, i.e. blood temperature, thermal conductivity, and blood perfusion rate on tissue temperature. The outcome of this study will be helpful for the researchers and physicians involved in the thermal treatment of human tissue.
\end{abstract}

Key words: bio-heat transfer; finite element method; Penne's equation; thermal therapy; external heating.

\section{Introduction}

Transferring thermal energy through external heating inside the biological tissue has remarkable success in many therapeutic treatments. Based on the amount of energy absorbed by the tissue and the nature of the heating, this process can serve as various biomedical problems i.e. malignant cell destruction, thermal comfort, burn analysis. This process is done by taking advantage of the lability of biological tissue at elevated temperatures. The design of such a modality strongly depends upon the knowledge of tissue response to thermal energy. Thus, acknowledgment of the thermal behavior of human tissue subjected to external power is utmost necessary. Undoubtedly experimental studies can provide such information closer to real scenarios. However, that requires suitable equipment and a proper experimental setup, which is costly as well as hazardous. Hence arises the necessity of mathematical modeling. With the advancement in computational methods and technology, its application in modeling biological systems has been a topic of interest by scientists and researchers. In modern days' mathematical models are widely used to ascertain safety issues in treating malignant cells, cryosurgery, laser eye surgery, etc. Moreover, due to its non-invasive nature and simplicity, it is welcomed by researchers and engineers.
Heat transfer in the biological tissue is governed by the bioheat equation. Several forms of the bio-heat equation can be found in the literature. Among them, the most popular and most widely used one is the Pennes Bio-heat equation. ${ }^{1}$ Uniform thermal conductivity, blood perfusion, and metabolism give it simplicity; that is why it is used in various biological research works.

Initially the Pennes bio-heat equation was developed to predict heat transfer in human forearm, but later on, it was used in various biological research works like human eye research ${ }^{2,3}$ and skin bio-heat transfer. ${ }^{4,5}$ This equation was used in modeling and optimization of temperature distribution around cancerous tissues during magnetic fluid hyperthermia, ${ }^{6,7}$ ultrasound thermal therapy. ${ }^{8,9}$ It was then used in determining tissue temperature by induced microwave, ${ }^{10}$ cryosurgery, ${ }^{11}$ and radio-frequency heating ${ }^{12,13}$ and laser heating ${ }^{14,15}$.

Various analytical and numerical solutions of the bio-heat equation can be found in the literature. In complex situations where analytical solutions are not available or very complicated, numerical methods are preferable, where an analytical solution works as a benchmark of numerical solutions. In many analytical solutions, a time-dependent green function is used in ${ }^{16,17}$, Finite Difference solution is obtained in ${ }^{8,10,18}$, Boundary Element Method in ${ }^{3}$, and the Finite Element Method in ${ }^{4,5}$. The analytical and numerical results under different spatial and surface heating can be found in the 
literature. In some cases, oscillatory surface heating ${ }^{18-21}$, step heating ${ }^{19,20}$, or constant surface heating ${ }^{19,20}$ is considered in the bioheat transfer analysis. Sometimes constant spatial heating, even sinusoidal spatial heating ${ }^{17,22-24}$ is used as external heating. Deng et al. and Sharma et al. used point heating as an external heat source. ${ }^{17,24}$ The alternating heating and cooling strategy was introduced by Yuan et al. ${ }^{25}$ Twodimensional bioheat transfer problem with a rectangular domain with and without tumor was analyzed by Leilei et $\mathrm{al}^{26}$ Constant and sinusoidal heat flux boundary condition was used for estimation of blood perfusion using phase shift in temperature response in ${ }^{27-29}$.

To the best of the authors' knowledge, most of the researchers concentrate on the one-dimensional case only. However, for a better understanding of the response of biological tissue to elevated temperature, it is beneficial to use a multidimensional heat transfer model. Three-dimensional cases of conventional heat transfer are available in the literatures ${ }^{30}$ but cases of skin burn were few and with the use of commercial softwares ${ }^{31}$. It is quite difficult to have the temperature profile of a particular point or a line within the biological tissue with different time intervals using that software. Moreover, they operate on limited boundary conditions. The development of a free two-dimensional finite element code of bio-heat equations can meet the purpose. The objective of this research is to develop a two-dimensional finite element code for the solution of both steady and transient bioheat equation. The popular Crank-Nicolson method was used in the time discretization of the transient analysis. The developed finite element code was used to simulate the thermal response of tissue during cancer hyperthermia, laser surgery, tissue heating with a hot disk, and point heating. Moreover, time-dependent spatial and surface heating were incorporated. The effect of surface heating, step heating, sinusoidal heating, and point heating was thoroughly investigated.

\section{Finite element discretization of bio heat equation}

\subsection{Bio Heat Equation}

To evaluate the temperature profile inside blood perfused tissue the most widely used Pennes Bio heat equation is used in this research. For the two-dimensional case, the equation can be expressed as:

$\mathrm{k} \frac{\partial^{2} \mathrm{~T}}{\partial \mathrm{x}^{2}}+\mathrm{k} \frac{\partial^{2} \mathrm{~T}}{\partial \mathrm{y}^{2}}+\omega_{\mathrm{b}} \rho_{\mathrm{b}} \mathrm{c}_{\mathrm{b}}\left(\mathrm{T}_{\mathrm{a}}-\mathrm{T}\right)+\mathrm{Q}_{\mathrm{m}}+\mathrm{Q}_{r}=\rho \mathrm{c} \frac{\partial \mathrm{T}}{\partial \mathrm{t}}$

Eq. 1

where, $\mathrm{k}$ is the thermal conductivity of the tissue, $\rho$ and $\mathrm{c}$ are the density and specific heat of the tissue respectively. And $\rho_{\mathrm{b}}$, $c_{b}$ denote density and specific heat of blood; $\omega_{b}$ is the blood perfusion; $\mathrm{T}_{\mathrm{a}}$ and $\mathrm{T}$ is the known arterial temperature and unknown tissue temperature respectively $; Q_{m}$ is the metabolic heat generation, and $Q_{r}$ is the heat source due to spatial heating with respect to time $t$.

\subsection{Finite element discretization}

The simplified form of Equation 1 can be simplified as:

$\mathrm{k} \frac{\partial^{2} \mathrm{~T}}{\partial \mathrm{x}^{2}}+\mathrm{k} \frac{\partial^{2} \mathrm{~T}}{\partial \mathrm{y}^{2}}+\mathrm{CT}_{a}+\mathrm{f}=\rho \mathrm{c} \frac{\partial \mathrm{T}}{\partial \mathrm{t}}$

Using the weighted residual method the weak form of the governing differential Equation 2 is derived as:

$0=\int_{\Omega_{\mathrm{e}}}\left[\mathrm{W} \rho \mathrm{c} \frac{\partial \mathrm{T}}{\partial \mathrm{t}}+\mathrm{k} \frac{\partial \mathrm{T}}{\partial \mathrm{x}} \frac{\partial \mathrm{w}}{\partial \mathrm{x}}+\mathrm{k} \frac{\partial \mathrm{T}}{\partial \mathrm{y}} \frac{\partial \mathrm{w}}{\partial \mathrm{y}}+\mathrm{CWT}-\mathrm{fW}\right] \mathrm{dA}-$

$\oint_{\Gamma_{\mathrm{e}}} \mathrm{W}\left(\mathrm{k} \frac{\partial \mathrm{T}}{\partial \mathrm{x}} \eta_{\mathrm{x}}+\mathrm{k} \frac{\partial \mathrm{T}}{\partial \mathrm{y}} \eta_{\mathrm{y}}\right) \mathrm{ds}$

Eq. 3

For a mixed boundary condition combing convective and heat flux boundary as $k \frac{\partial T}{\partial x} \eta_{x}+k \frac{\partial T}{\partial y} \eta_{y}=-\mathrm{h}\left(T-T_{0}\right)+q$,

Equation 3 was modified as follows to account for the convective heat transfer term. Here, $h$ is the convective heat transfer coefficient, $T_{\infty}$ is the ambient temperature, and $\mathrm{q}$ is the heat flux. And $\Omega_{\mathrm{e}}$ is the element domain and $\Gamma_{\mathrm{e}}$ is the boundary of the element.

$0=\int_{\Omega_{\mathrm{e}}}\left[w \rho c \frac{\partial T}{\partial t}+k \frac{\partial w}{\partial x} \frac{\partial T}{\partial x}+k \frac{\partial w}{\partial y} \frac{\partial T}{\partial y}+C w T-w f\right] d x d y-$ $w \oint_{\Gamma_{\mathrm{e}}}\left[q_{n}-h\left(T-T_{o}\right)\right] d s$ Eq. 4

Taking a finite element approximation as $\mathrm{T}=\sum_{\mathrm{j}=1}^{\mathrm{e}} \mathrm{T}_{\mathrm{j}}^{\mathrm{e}} \psi_{\mathrm{j}}^{\mathrm{e}}$ Equation $\mathbf{4}$ can be derived as:

$0=\int_{\Omega_{\mathrm{e}}} \rho c \psi_{i}^{e} \psi_{j}^{e} \frac{\partial T_{j}^{e}}{\partial t} d x d y+\int_{\Omega_{\mathrm{e}}}\left[\left\{k \frac{\partial \psi_{i}^{e}}{\partial x} \frac{\partial \psi_{j}^{e}}{\partial x}+k \frac{\partial \psi_{i}^{e}}{\partial y} \frac{\partial \psi_{j}^{e}}{\partial y}+\right.\right.$ $\left.\left.C \psi_{i}^{e} \psi_{j}^{e}\right\} d x d y+\oint_{\Gamma_{\mathrm{e}}} h \psi_{i}^{e} \psi_{j}^{e} d s\right] T_{j}^{e}-\int_{\Omega_{\mathrm{e}}} f \psi_{i}^{e} d x d y-$ $\oint_{\Gamma_{\mathrm{e}}}^{e} \psi_{i}^{e} h T_{0} d s-\oint_{\Gamma_{\mathrm{e}}}^{e} \psi_{i}^{e} \mathrm{q} d s$ Eq. 5

Here $i$ and $j$ donate the element number which ranges from 1 to $\mathrm{N}$, where $\mathrm{N}$ is the total no of elements. Finally, the finite element model of the governing differential equation is derived as follows:

$0=\sum_{j=1}^{N}\left\{\int_{\Omega_{\mathrm{e}}} \rho c \psi_{i}^{e} \psi_{j}^{e} \frac{\partial T_{j}^{e}}{\partial t} d x d y+\int_{\Omega_{\mathrm{e}}}\left[\left\{k \frac{\partial \psi_{i}^{e}}{\partial x} \frac{\partial \psi_{j}^{e}}{\partial x}+\right.\right.\right.$

$\left.\left.k \frac{\partial \psi_{i}^{e}}{\partial y} \frac{\partial \psi_{j}^{e}}{\partial y}+C \psi_{i}^{e} \psi_{j}^{e}\right\} d x d y+\oint_{\Gamma_{\mathrm{e}}} h \psi_{i}^{e} \psi_{j}^{e} d s\right] T_{j}^{e}-$

$\left.\int_{\Omega_{\mathrm{e}}} f \psi_{i}^{e} d x d y-\oint_{\Gamma_{\mathrm{e}}} \psi_{i}^{e} h T_{o} d s-\oint_{\Gamma_{\mathrm{e}}} \psi_{i}^{e} q d s\right\}$

A simplified form of Equation 6 can be written as:

$0=\sum_{j=1}^{N}\left\{C_{i j}^{e} \dot{T}_{j}^{e}+\left[K_{i j}^{e}+H_{i j}^{e}\right] T_{j}^{e}-q_{i}^{e}-Q_{i}^{e}-P_{i}^{e}\right\}$

Here,

$C_{i j}^{e}=\int_{\Omega_{e}} \rho c \psi_{i}^{e} \psi_{j}^{e}$

$\mathrm{K}_{\mathrm{ij}}^{\mathrm{e}}=\int_{\Omega_{\mathrm{e}}} \mathrm{k} \frac{\partial \psi_{\mathrm{i}}^{\mathrm{e}}}{\partial \mathrm{x}} \frac{\partial \psi_{\mathrm{j}}^{\mathrm{e}}}{\partial \mathrm{x}}+\mathrm{k} \frac{\partial \psi_{\mathrm{i}}^{\mathrm{e}}}{\partial \mathrm{y}} \frac{\partial \psi_{\mathrm{j}}^{\mathrm{e}}}{\partial \mathrm{y}}+\mathrm{C} \psi_{\mathrm{i}}^{\mathrm{e}} \psi_{\mathrm{j}}^{\mathrm{e}}$

$\mathrm{H}_{\mathrm{ij}}^{\mathrm{e}}=\oint_{\Gamma_{\mathrm{e}}} \mathrm{h} \psi_{\mathrm{i}}^{\mathrm{e}} \psi_{\mathrm{j}}^{\mathrm{e}}$

$q_{i}^{e}=\int_{\Omega_{e}} f \psi_{i}^{e} d A$ 
$\mathrm{P}_{\mathrm{i}}^{\mathrm{e}}=\oint_{\Gamma_{\mathrm{e}}} \mathrm{q}_{\mathrm{f}} \psi_{\mathrm{i}}^{\mathrm{e}} \mathrm{ds}$

$\mathrm{Q}_{\mathrm{i}}^{\mathrm{e}}=\oint_{\Gamma_{\mathrm{e}}} \mathrm{h}_{0} \mathrm{~T}_{0} \psi_{\mathrm{i}}^{\mathrm{e}} \mathrm{ds}$

In matrix notation, the finite element model can be expressed as:

$[\mathbf{C}]\{\dot{\mathbf{T}}\}+[\mathbf{K}]\{\mathbf{T}\}=\{\mathbf{q}\}+\{\mathbf{Q}\}+\{\mathbf{P}\}$

Eq. 8

where, $[\mathrm{C}]$ is the capacitance matrix and $[\mathrm{K}]$ is the conductivity matrix and $\dot{\mathrm{T}}=\frac{\mathrm{T}^{\mathrm{n}+1}-\mathrm{T}^{\mathrm{n}}}{\Delta \mathrm{t}}$.

\subsection{Time discretization}

A simple time integration scheme for Equation $\mathbf{8}$ is derived by assuming that $\mathrm{C}$ and $\mathrm{K}$ are constant. In such a case, the matrix differential equation can be discretized with the response to time as:

$\mathrm{C} \frac{\mathrm{T}^{\mathrm{n}+1}-\mathrm{T}^{\mathrm{n}}}{\Delta \mathrm{t}}+\alpha \mathrm{KT}^{\mathrm{n}+1}+(1-\alpha) \mathrm{KT}^{\mathrm{n}}=\mathrm{Q}+\mathrm{q}+\mathrm{P}$

Eq. 9

where $\mathbf{T}^{\mathbf{n}+\mathbf{1}}$ and $\mathbf{T}^{\mathbf{n}}$ are the vectors of unknown nodal temperature values at times $\mathbf{n} \Delta \mathbf{t}$ and $(\mathbf{n}+\mathbf{1}) \Delta \mathbf{t}$, respectively and $\alpha$ is the weighting factor, which must be chosen in the interval between 0 and 1 . When the value of $\alpha$ is considered 0.5 , the process is called the popular Crank-Nicolson method. The discretized Equation 9 can be written as:

$\left(C \frac{1}{\Delta T}+\alpha K\right) T^{n+1}=\left[C \frac{1}{\Delta T}-(1-\alpha) K\right] T^{n}+q+Q+P$ Eq. 10

Equation 10 was solved using an iterative procedure. The initial temperature is known and then the temperature of the next step can be calculated from the solution of Eq. (10) through the Gauss elimination technique.

\section{Computational model}

\subsection{Tissue model}

Our two-dimensional computational model of the human tissue is shown in Figure 1. Here $X=0$ is the skin surface, and $X=L_{1}$ is the body core. $\mathrm{L}_{1}$ is the problem length along the $\mathrm{X}$-axis and $\mathrm{L}_{2}$ is the length along $\mathrm{Y}$-axis.

\subsection{Boundary Conditions}

The skin surface is in contact with the environment, hence heat exchange between the environment and skin surface is a convection process. So the boundary condition at the skin surface is governed by

$\mathrm{k} \frac{\partial \mathrm{T}}{\partial \mathrm{x}} \eta_{\mathrm{x}}+\frac{\partial \mathrm{T}}{\partial \mathrm{y}} \eta_{\mathrm{y}}=-\mathrm{h}_{0}\left(\mathrm{~T}_{\mathrm{o}}-\mathrm{T}\right)$ on $\Gamma_{1}$

Eq. 11.1

Here $\mathrm{h}_{0}$ is the ambient heat transfer coefficient, and $\mathrm{T}_{0}$ is the ambient temperature.
In some cases, water is circulated over the skin surface to reduce the skin surface temperature. The forced convection boundary condition in such cases can be expressed as

$\mathrm{k} \frac{\partial \mathrm{T}}{\partial \mathrm{x}} \eta_{\mathrm{x}}+\frac{\partial \mathrm{T}}{\partial \mathrm{y}} \eta_{\mathrm{y}}=-\mathrm{h}_{\mathrm{f}}\left(\mathrm{T}_{f}-\mathrm{T}\right)$ on $\Gamma_{1}$

Here $h_{f}$ is the forced convection coefficient between the environment and tissue, and $\mathrm{T}_{\mathrm{f}}$ is the cold water temperature.

In the case of surface heating, the skin surface is exposed to the applied heat flux. So the boundary condition in such a case can be expressed as:

$\mathrm{k} \frac{\partial \mathrm{T}}{\partial \mathrm{x}} \eta_{\mathrm{x}}+\frac{\partial \mathrm{T}}{\partial \mathrm{y}} \eta_{\mathrm{y}}=-q_{f}$ on $\Gamma_{1}$

Eq. 11.3

Here $\mathrm{q}_{\mathrm{f}}$ is the applied heat flux, which can be both constant and time-dependent.

Both sides of the $\mathrm{Y}$-Axis $\mathrm{Y}=0$ and $\mathrm{Y}=30 \mathrm{~mm}$ is considered as thermally insulated. No heat transfer occurs through those boundaries, therefore:

$\mathrm{k} \frac{\partial \mathrm{T}}{\partial \mathrm{x}} \eta_{\mathrm{x}}+\frac{\partial \mathrm{T}}{\partial \mathrm{y}} \eta_{\mathrm{y}}=0$ on $\Gamma_{2}$

Eq. 11.4

Tissue temperature within a narrow range tends to keep constant the same as the body core temperature. Thus, considering $T_{c}$ as the body core temperature, the boundary condition at the body core is expressed as:

$\mathrm{T}=\mathrm{T}_{\mathrm{c}}$ on $\Gamma_{3}$

Eq. 11.5

In all the numerical investigations, the boundary condition Equation $\mathbf{1 1 . 5}$ is the temperature boundary condition used at the body core $\left(\Gamma_{3},\right)$. Equation 11.4 used both sides of the $Y$ axis $\left(\Gamma_{2}\right.$ and $\left.\Gamma_{4}\right)$. However, based upon the heating and cooling conditions the natural convection boundary condition (Equation 11.1), forced convection boundary condition (Equation 11.2) and heat flux boundary condition (Equation 11.3) are applied at the skin surface $\left(\Gamma_{1}\right)$ as the boundary condition.

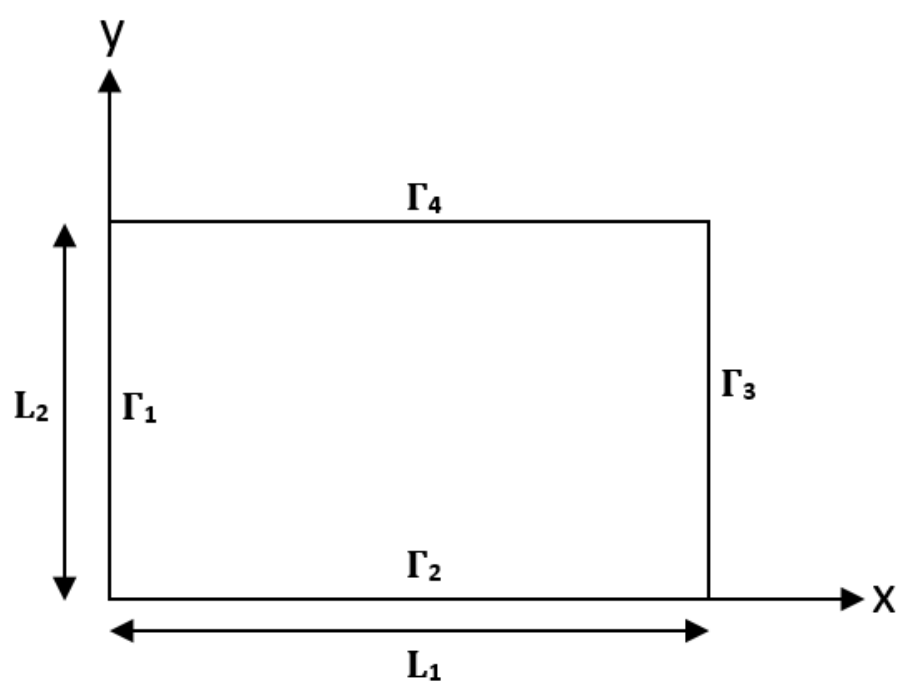

Figure 1. Human Tissue Model 


\subsection{Mesh and materials properties}

The tissue properties and values of other control parameters used in this study are summarized in Table $\mathbf{1}$ as given in ${ }^{32}$. As tissue temperature tends to keep constant within a narrow range, such as for $20 \mathrm{~mm}$ to $30 \mathrm{~mm}$. Our problem domain length is considered as $30 \mathrm{~mm}$ for both axes, so $\mathrm{L}_{1}=30 \mathrm{~mm}$ and $\mathrm{L}_{2}=30 \mathrm{~mm}$. The linear triangular element was used for space discretization. Moreover, in this study, the body core temperature is considered as $37^{\circ} \mathrm{C}$. Besides, the initial temperature (at $\mathrm{t}=0$ ) of all nodes is considered $37^{\circ} \mathrm{C}$. For the transient solution, a time step of $0.25 \mathrm{~s}$ is considered in this study.

\subsection{Code Validation}

Before using the computer program for further investigation, it is necessary to verify it with the analytic solution. For this purpose, we develop a test problem considering the following boundary conditions of the problem described in Figure 1. The analytical result for the steady-state problem is calculated from Equation 12. The typical tissue properties used in this section are summarized in Table 1. In this case, heat generation due to metabolism is ignored; hence $\mathrm{Q}_{\mathrm{m}}$ is considered as 0 .

Boundary conditions for the test problem are as below:

$\mathrm{T}=37^{0} \mathrm{C}$ on $\Gamma_{3} ; \mathrm{T}=45^{0} \mathrm{C}$ on $\Gamma_{1} ; \mathrm{k} \frac{\partial \mathrm{T}}{\partial \mathrm{x}} \eta_{\mathrm{x}}+\frac{\partial \mathrm{T}}{\partial \mathrm{y}} \eta_{\mathrm{y}}=0$ on $\Gamma_{2}$ and $\mathrm{k} \frac{\partial \mathrm{T}}{\partial \mathrm{x}} \eta_{\mathrm{x}}+\frac{\partial \mathrm{T}}{\partial \mathrm{y}} \eta_{\mathrm{y}}=0$ on $\Gamma_{4}$

For the steady-state case, the analytical result is derived from the following expression ${ }^{33}$ :

$\mathrm{T}(\mathrm{x})=\mathrm{T}_{\mathrm{a}}+\frac{\left(\mathrm{T}_{\mathrm{S}}-\mathrm{T}_{\mathrm{a}}\right) \sinh \left[\mu\left(\mathrm{L}_{1}-\mathrm{x}\right)\right]+\left(\mathrm{T}_{\mathrm{c}}-\mathrm{T}_{\mathrm{a}}\right) \sinh (\mu \mathrm{x})}{\sinh \left(\mu \mathrm{L}_{1}\right)}$

Eq. 12

where, $\mu=\sqrt{\left(\omega_{b} \rho_{b} C_{b}\right)} ; T_{s}=$ skin surface temperature; $L_{1}=$ problem length along $\mathrm{X}$-axis.

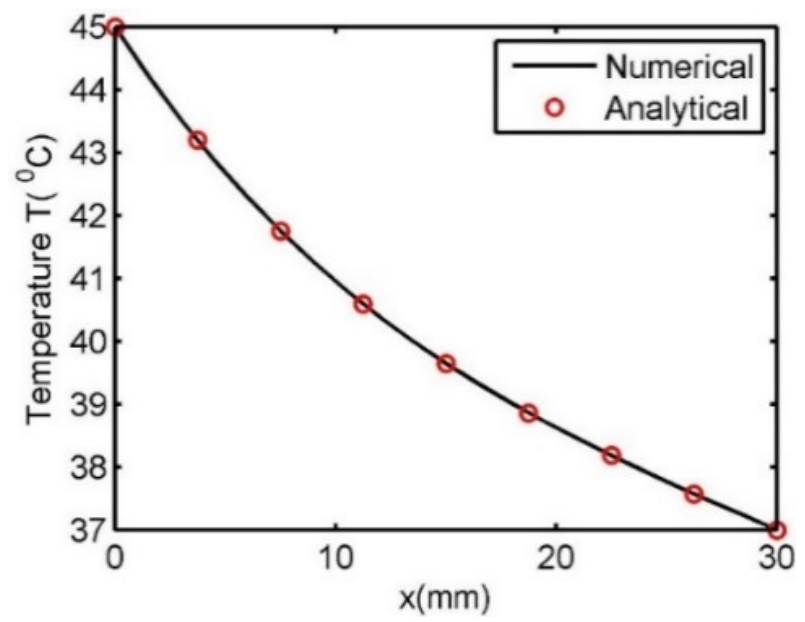

Figure 2. Code verification (Steady-State Case)
Table 1. Thermal Properties of biological tissue and values of control parameters

\begin{tabular}{ccc}
\hline \hline Parameters & Symbol & Value \\
\hline Thermal conductivity & $\mathrm{k}$ & $0.5 \mathrm{~W} /\left(\mathrm{m} \cdot{ }^{\circ} \mathrm{C}\right)$ \\
Convection Coefficient & $\mathrm{h}_{\mathrm{o}}$ & $10 \mathrm{~W} /\left(\mathrm{m}^{2} \cdot{ }^{\circ} \mathrm{C}\right)$ \\
Forced convection coefficient & $\mathrm{h}_{\mathrm{f}}$ & $100 \mathrm{~W} /\left(\mathrm{m}^{2} \cdot{ }^{\circ} \mathrm{C}\right)$ \\
Environmental Temperature & $\mathrm{T}_{0}$ & $25^{\circ} \mathrm{C}$ \\
Temperature of the Artery & $\mathrm{T}_{\mathrm{a}}$ & $37^{\circ} \mathrm{C}$ \\
Body core temperature & $\mathrm{T}_{\mathrm{c}}$ & $37^{\circ} \mathrm{C}$ \\
Metabolic heat generation & $\mathrm{Q}_{\mathrm{m}}$ & $33800 \mathrm{~W} / \mathrm{m}^{2}$ \\
Density of blood & $\rho_{\mathrm{b}}$ & $1000 \mathrm{~kg} / \mathrm{m}^{3}$ \\
Density of tissue & $\mathrm{P}$ & $1000 \mathrm{~kg} / \mathrm{m}^{3}$ \\
Specific heat of blood & $\mathrm{c}_{\mathrm{b}}$ & $4200 \mathrm{~J} /\left(\mathrm{kg} \cdot{ }^{\circ} \mathrm{C}\right)$ \\
Specific heat of the tissue & $\mathrm{c}$ & $4200 \mathrm{~J} /\left(\mathrm{kg} \cdot{ }^{\circ} \mathrm{C}\right)$ \\
Blood perfusion & $\omega_{\mathrm{b}}$ & $0.0005 \mathrm{~m} / \mathrm{s} / \mathrm{m}^{3}$ \\
Laser Heating Power & $\mathrm{P}_{0}$ & $2500 \mathrm{~W} / \mathrm{m}^{2}$ \\
Point Heating Power & $\mathrm{P}_{1}$ & $2500 \mathrm{~W} / \mathrm{m}^{2}$ \\
Scattering Coefficient & $\eta$ & $200 \mathrm{~s}-1$ \\
Heat Flux & $\mathrm{q}_{\mathrm{f}}$ & $1000 \mathrm{~W} / \mathrm{m}^{2}$ \\
\hline \hline
\end{tabular}

The steady and transient temperature (after the $2000 \mathrm{~s}$ ) in comparison with other analytical and numerical results available in the literature is shown in Figure 2 and Figure 3, respectively. A good agreement with the analytical result is found in Figure 2. While a slight deviation of our transient solution from analytical results ${ }^{26}$ is noticed in Figure 3. However, our result seems better than Treffetz-FEM and RBFMFS results.

\section{Computational results and discussion}

\subsection{Spatial heating}

Laser therapy uses a strong beam of light to cut, burn, or destroy tissue. It is delivered from a safe source. That is why it poses no health risks to the patient or the medical team. The laser beam is tiny and precise, hence allows doctors to treat tissue without injuring the surrounding area. Laser therapy can be used to treat cervical, lung, and skin cancer. Along with laser, microwaves are also used in non-surgical, minimally invasive therapy.

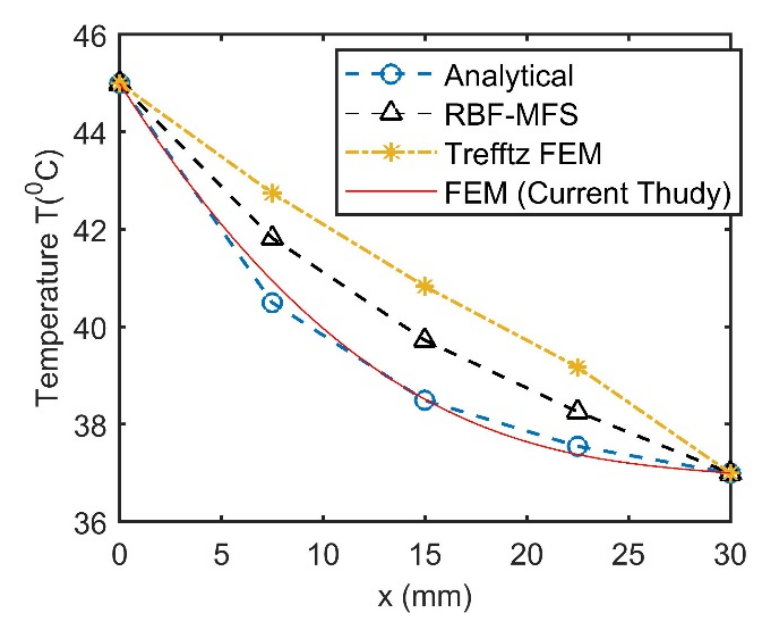

Figure 3. Code verification (Transient Case) 
In this section, we aim to know the response of biological tissue to laser or microwave heating. For this purpose, we consider convection boundary condition at the skin surface and temperature boundary condition at the body core, and laser or microwave power is used as external heating.

In the case of heating by laser and microwave, the heat absorption rate can be simplified by Beers Law, which can be expressed as $Q_{r}=\eta P_{0}(t) e^{-\eta x} \cdot{ }^{34}$ Where, $P_{o}(t)$ is the timedependent heating power on the skin surface and $\eta$ is the scattering coefficient. Since $\mathrm{P}_{0}(\mathrm{t})$ and $\eta$ vary from one apparatus to another, so it is important to know the influence of these parameters on tissue temperature. $P_{o}(t)$ can be both constant and time-dependent. In this study, tissue temperature is calculated considering both cases. In addition, the natural convection boundary condition (Equation 11.1) is used here as the skin surface boundary condition. Figure 4 depicts the transient temperature at various times along the $\mathrm{x}$-axis when tissues subject to spatial heating. Figure $4 \mathbf{a}$ shows the case of constant spatial heating where heating power $\mathrm{P}_{0}(\mathrm{t})=250 \mathrm{~W} / \mathrm{m}^{2}$ and while Figure $\mathbf{4 b}$ is for sinusoidal spatial heating where $\mathrm{P}_{0}(\mathrm{t})=250+200 \cos (0.02 \mathrm{t}) \mathrm{W} / \mathrm{m}^{2}$. In both cases, at the early

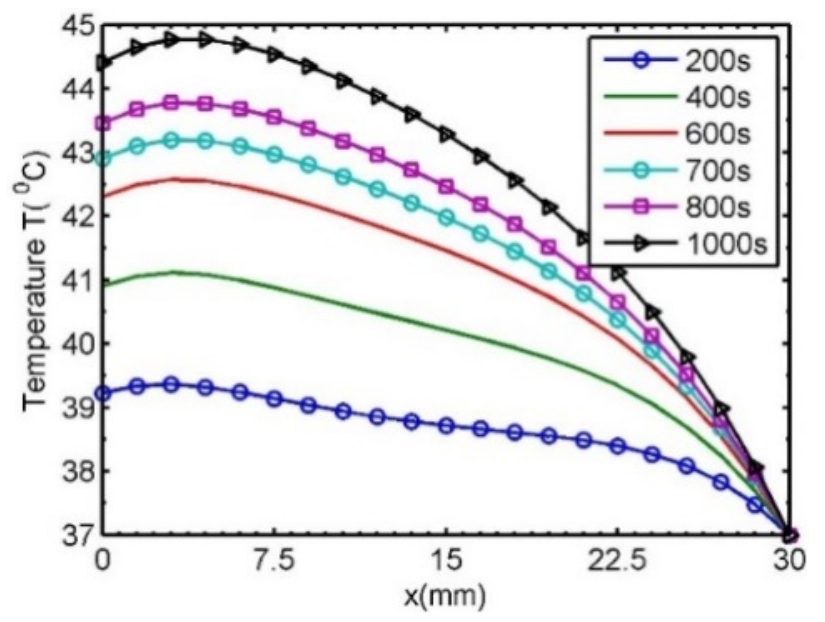

(a) stage, the tissue temperature increases along with the distance from the skin surface due to metabolism and spatial heating but later it decreases towards the body core. Moreover, an intercross is noticed between temperature curves at different times in Figure $\mathbf{4 b}$, which indicates the oscillation of the temperature inside the tissue over time due to sinusoidal spatial heating. Here the maximum temperature lies approximately $7 \mathrm{~mm}$ below the skin surface. But in Figure 4a it lies below $11 \mathrm{~mm}$. Thus, the laser heating shifts the point of maximum temperature near the skin surface.

Figure 5 shows the effect of the scattering coefficient. Where, Figure 5a shows the result of constant spatial heating and Figure 5b shows the sinusoidal case. Both figures show an increasing trend in temperature over time. However, the increasing rate decreases as time passes. In both cases, the larger coefficient results in a higher temperature. Moreover, in the case of sinusoidal spatial heating, the larger coefficient returns a higher amplitude. It is to be noted that the sinusoidal effect is clearly visible from Figure 5b. Besides, under the current set up, tissue temperature begins to stabilize approximately after $3000 \mathrm{~s}$.

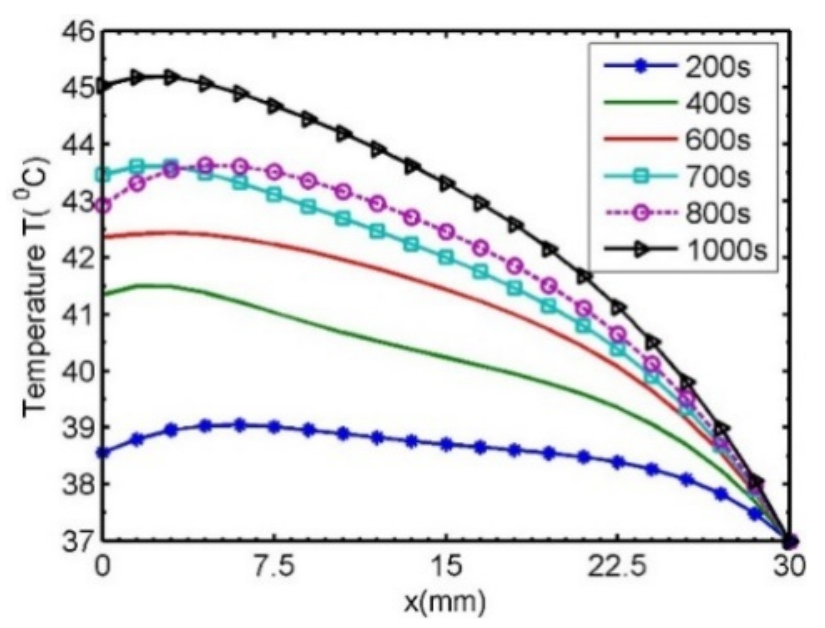

(b)

Figure 4. Temperature along with time (a) $P_{0}(t)=250 \mathrm{~W} / \mathrm{m}^{2}$; (b) $250+200 \cos (0.02 t) \mathrm{W} / \mathrm{m}^{2}$.

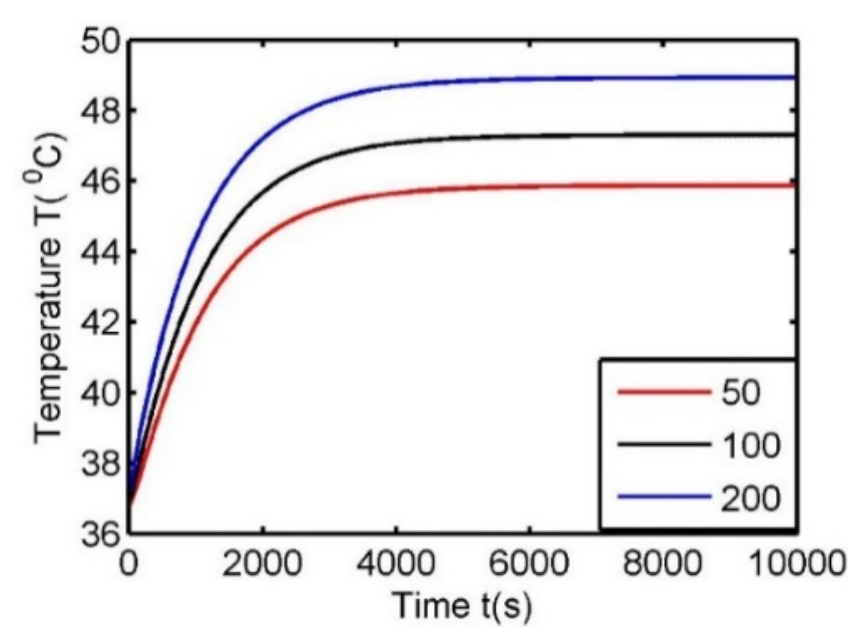

(a)

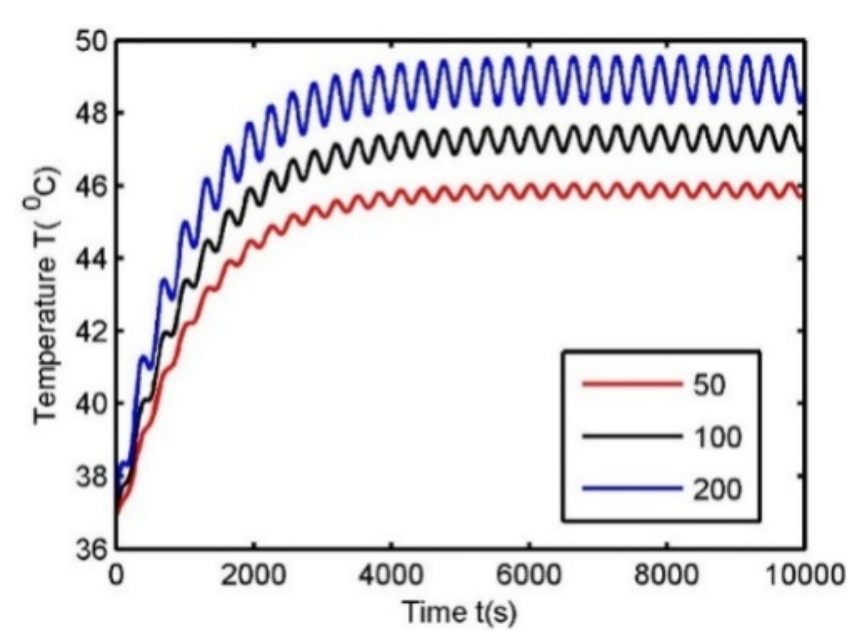

(b)

Figure 5. Effect of Scattering Coefficient (a) $P_{0}(t)=250 \mathrm{~W} / \mathrm{m} 2 ;$ (b) $250+200 \cos (0.02 t) \mathrm{W} / \mathrm{m}^{2}$. 


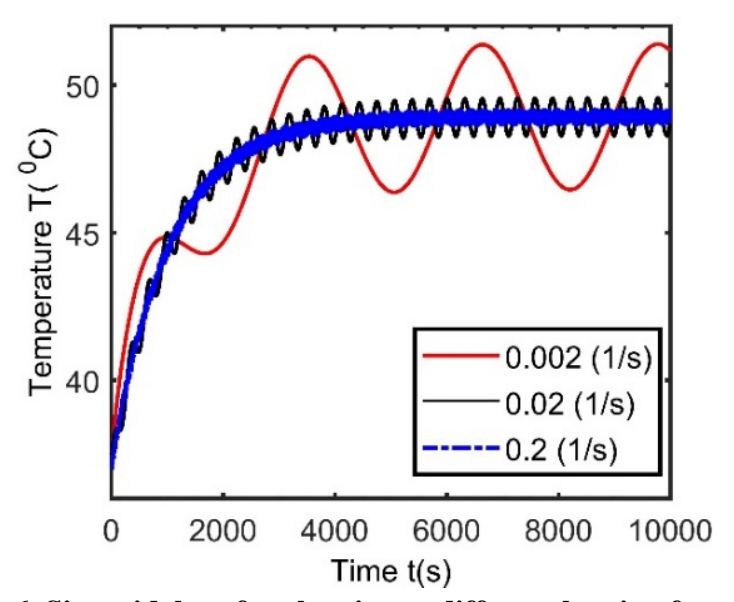

Figure 6. Sinusoidal surface heating at different heating frequency $(P 0(t)=250+200 \cos (\omega t)) W / m^{2}$

\subsubsection{Effect of heating frequency}

Figure 6 shows the temperature distribution inside the human tissue subject to sinusoidal spatial heating for three different heating frequencies. The sinusoidal oscillation of tissue temperature is clearly visible in all three curves. Apparently, the larger heating frequency decreases temperature fluctuation. However, it does not have any significant effect on the tissue temperature instead it changes the wavelength and frequency. Such kind of information is significant in the case of parameter estimation.

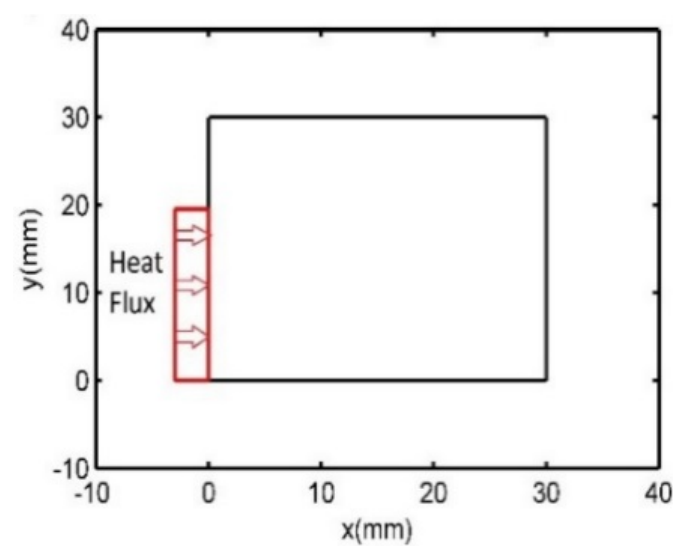

(a)

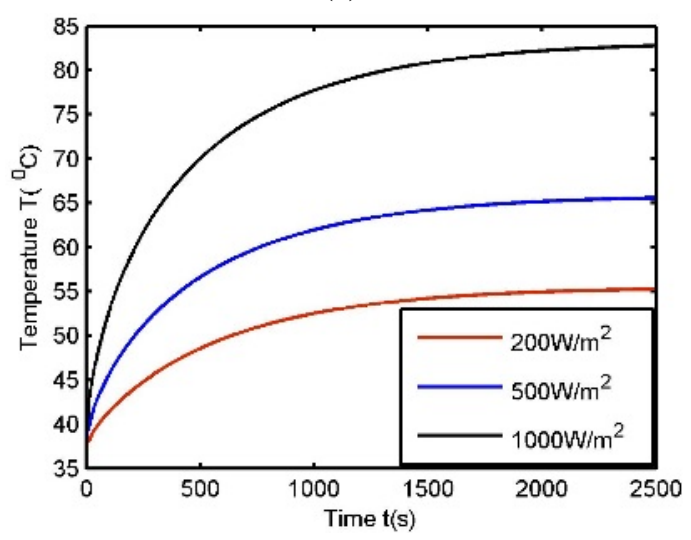

(c)

\subsection{Surface Heating}

The practical application of this type of heating can be found in the case of industrial accidents when human tissue is exposed to hot fluid or flash flame or in contact with a hot object. Moreover, in hyperthermia treatment, this can be used for increasing blood perfusion rate and metabolism. Surface heating is also used in thermal burn injuries or thermal comfort analysis. To investigate the temperature distribution during surface heating, we used a heating plate that delivers heat flux continuously to the skin tissue at a constant rate. Heat flux boundary condition is used here at the skin surface as a boundary condition. Figure 7a shows our tissue model with a heating plate. Tissue temperature after $1000 \mathrm{~s}$ due to heating with a hot plate is shown in Figure $7 \mathbf{b}\left(q_{\mathrm{f}}=1000 \mathrm{~W} / \mathrm{m}^{2}\right)$. Where tissue temperature along time for three different heat fluxes is shown in Figure 7c. Moreover, tissue temperature along with the distance from the skin surface at different times is shown in Figure 7d. It is clearly visible in Figures $\mathbf{7 b}$ and $\mathbf{7 d}$ that tissue layers adjacent to the heat source are affected more significantly than others, which results in a hot temperature region at the skin surface. Moreover, temperature declined from the skin surface to the body core. Here, from Figure 7c the maximum recorded temperature after $2500 \mathrm{~s}$ for $\mathrm{q}_{\mathrm{f}}=1000 \mathrm{~W} / \mathrm{m}^{2}$ is almost $83^{\circ} \mathrm{C}$. For $\mathrm{q}_{\mathrm{f}}=500 \mathrm{~W} / \mathrm{m}^{2}$ the maximum temperature decreases to $65^{\circ} \mathrm{C}$ and for $\mathrm{q}_{\mathrm{f}}=200 \mathrm{~W} / \mathrm{m}^{2}$ it is $55^{\circ} \mathrm{C}$.

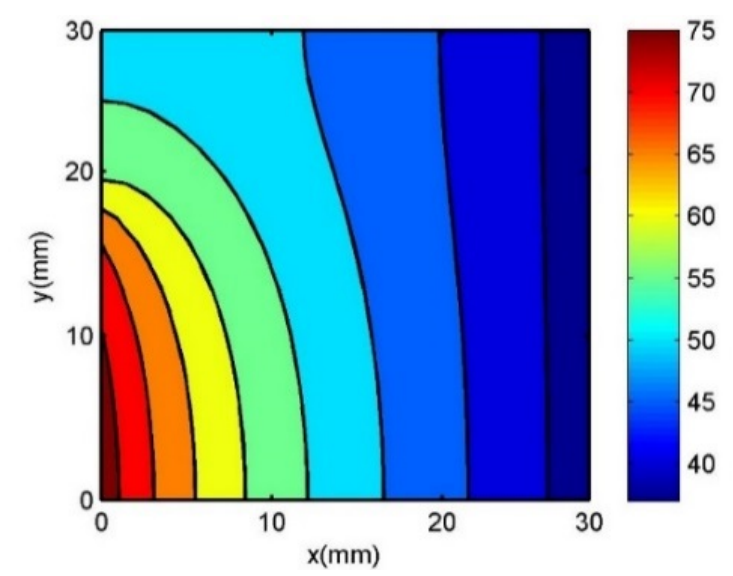

(b)

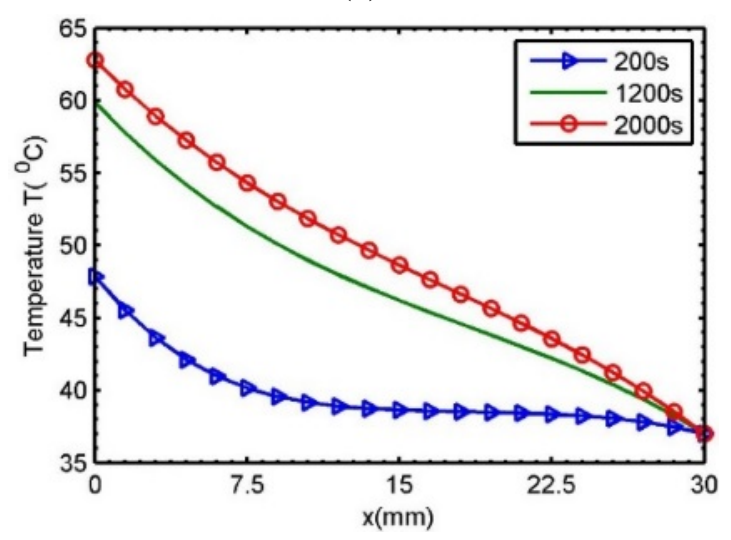

(d)

Figure 7. Temperature profile of human tissue during surface heating; (a) Model (b) Tissue temperature at $q_{f}=1000 \mathrm{~W} / \mathrm{m}^{2}(c)$ Tissue temperature along time at three different heat flux (d) Tissue temperature along distance at $q_{\mathrm{f}}=1000 \mathrm{~W} / \mathrm{m}^{2}$ 
So, depending upon the required temperature a combination between heat flux and exposure duration can be made using this result. For high heat flux, there is a great possibility of skin burn due to high temperature. So careful heating is necessary in the case of thermal therapy.

\subsubsection{Step heating}

In some cases, the tissue is heated in two stages one is the heating stage and another is the cool-down stage. In the cooldown stage heat source becomes idle and allows tissues to cool. This type of scenario is considered in this section. Figure 8 shows the effect of step heating at three different locations of the tissue $\mathrm{x}=0 \mathrm{~mm}, 15 \mathrm{~mm}$, and $30 \mathrm{~mm}$ while $\mathrm{y}=0$ $\mathrm{mm}$. Here Figure 8a shows the result when tissue is heated in one step, where Figure $\mathbf{8 b}$ represents the tissue temperature when tissue is heated in two steps. After heating up to $500 \mathrm{~s}$ heat source is removed, the heat source again becomes active after $1000 \mathrm{~s}$ and heated up to $1500 \mathrm{~s}$. The external heat source for both cases is expressed as below

For single-step heating $\mathrm{q}_{\mathrm{f}}=\left\{\begin{array}{l}1000 \mathrm{Wm}^{-2} \text { if } \mathrm{t}<1200 \mathrm{~s} \\ 0 \text { if } \mathrm{t}>1200 \mathrm{~s}\end{array}\right.$

For double step heating $\mathrm{q}_{\mathrm{f}}=\left\{\begin{array}{l}1000 \mathrm{Wm}^{-2} \text { if } \mathrm{t}<500 \text { s or } 1000 \mathrm{~s}<t<1500 \mathrm{~s} \\ 0 \text { Otherwise }\end{array}\right.$

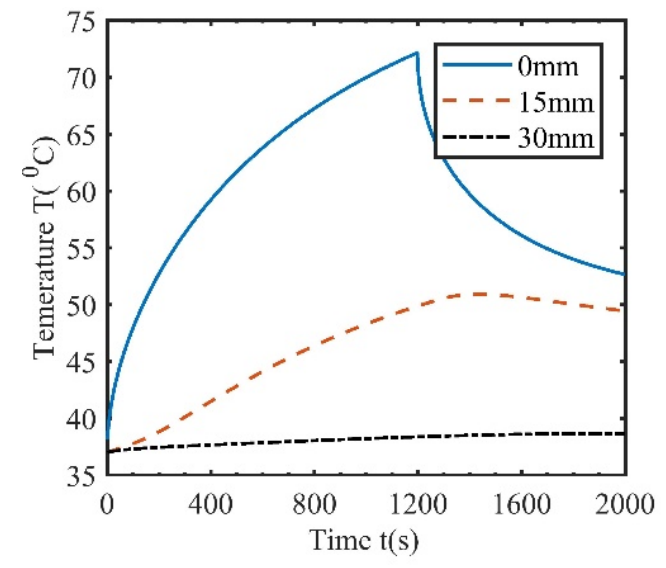

(a)
Figure 8a shows that the temperature increases along time up to 1200 s and decreases afterward as the heat source is idle at that time. However, both figures draw a similar conclusion, and that is tissue temperature increases as time increases and distance from the skin surface decreases.

\subsubsection{Sinusoidal surface heating}

Figure 9 shows the temperature distribution subject to sinusoidal surface heating where $\mathrm{q}_{\mathrm{f}}=1000+500 \cos (\omega \mathrm{t})$, here $\omega$ is the heating frequency $\left(0.02 \mathrm{~s}^{-1}\right)$. Figure 9a shows the result along time. The three curves show the result for three different locations of $X=0 \mathrm{~mm}, 15 \mathrm{~mm}$, and $30 \mathrm{~mm} \mathrm{~m}$ (Here $Y=0 \mathrm{~mm}$ ). Meanwhile, Figure 9b shows the temperature inside human tissue at three different blood perfusion rates. From Figure 9a, the frequency of the oscillating temperature decreases when we move from the skin surface to towards the body core (From $X=0 \mathrm{~mm}$ to $X=30 \mathrm{~mm}$ ). Figure $9 b$ shows that higher blood perfusion results in a decrease of tissue temperature as much heat is carried away by blood vessels.

Figure 8. Temperature distribution of human tissue during step heating at three different locations of $\mathbf{x}, 0 \mathrm{~mm}, 15 \mathrm{~mm}$, and $30 \mathrm{~mm}$; (a) $q_{f}=1000 \mathrm{~W} / \mathrm{m}^{2}($ When $\mathrm{t}<1200 \mathrm{~s})$ else $\mathbf{q}_{\mathrm{f}}=0$; (b) $\mathbf{q}_{\mathrm{f}}=1000 \mathrm{~W} / \mathrm{m}^{2}$ (When $\mathrm{t}<500 \mathrm{~s}$ and $\left.1000 \mathrm{~s}<\mathrm{t}<1500 \mathrm{~s}\right)$ else $\mathbf{q}_{\mathrm{f}}=0$;

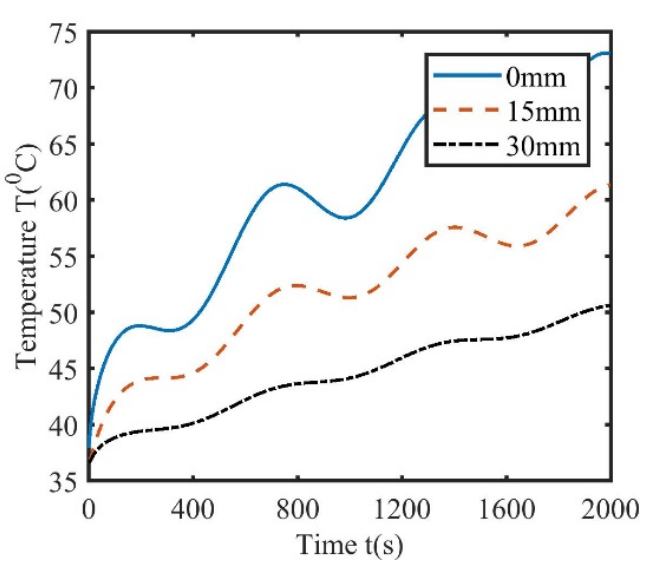

(a)

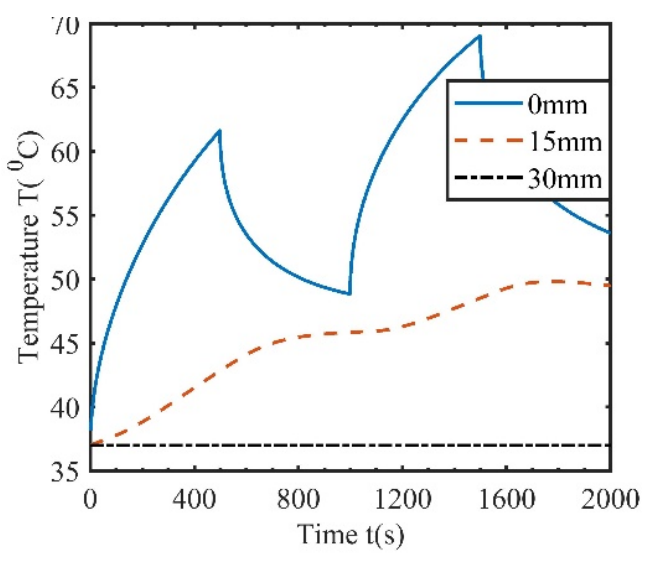

(b)

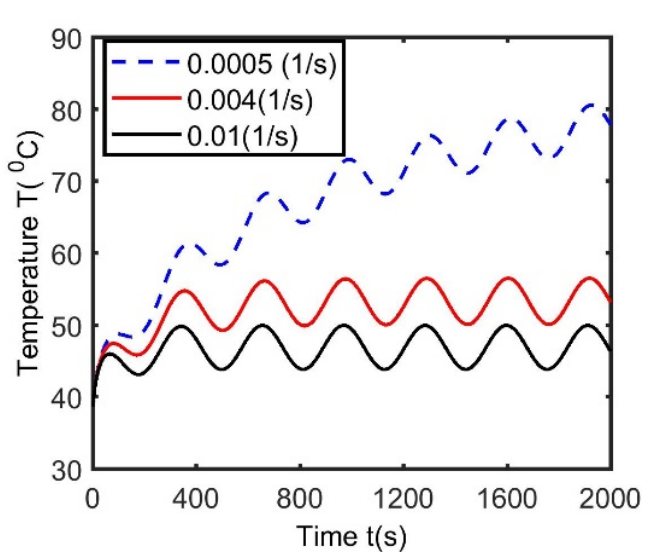

(b)

Figure 9. Sinusoidal surface heating; (a) Tissue temperature along distance and time (b) Tissue temperature at three different blood perfusion 


\subsection{Effect of irregular heating frequency}

The thermal response of tissue subject to simultaneously surface and spatial heating is shown in Figure 10. Here the expression of surface and special heating are used as $\mathrm{q}_{\mathrm{f}}=$ $1000+500 \quad \cos (0.02 \mathrm{t})$ and $\mathrm{P}_{0}(\mathrm{t})=250+200 \quad \cos (0.01 \mathrm{t})$ respectively. From Figure 10, curve A shows the result of sinusoidal spatial heating $\left(\omega=0.01 \mathrm{~s}^{-1}\right)$, curve B of sinusoidal surface heating $\left(\omega=0.02 \mathrm{~s}^{-1}\right)$. While in curve $\mathrm{C}$ both surface and spatial heating are applied simultaneously. From this figure, curve $\mathrm{A}$ and curve $\mathrm{B}$ bears the frequency of the external heating. However, irregular frequency is noticed from Curve C, which bears both frequencies. Such information is useful for selecting the appropriate heating pattern. Moreover, those results can be used in parameter estimation also.

\subsection{Point Heating}

In treating deep tumors located at the kidney, lung, or rectum, it is challenging to adopt surgical treatment. In such a case, point heating is an alternative to surgical operations. In this heating style, the total heating power deposits at the tumor site. There is an inverse relationship between elevated temperature and exposure duration. For the same amount of tissue necrosis, a high temperature needs low exposure duration. On the contrary, a low temperature needs high exposure duration. So, for effective thermal treatment, it is necessary to evaluate the required temperature and exposure duration precisely. Moreover, in some cases, to protect the skin surface cells from excess heat, cooling water is circulated over the skin surface during treatment.

To deposit total heating power at the desired site, the expression of the external heating was used like as ${ }^{17}$.

$\mathrm{Q}_{\mathrm{r}}(\mathrm{x}, \mathrm{t})=\mathrm{P}_{1}(\mathrm{t}) \delta\left(\mathrm{x}-\mathrm{x}_{0}\right) \delta\left(\mathrm{y}-\mathrm{y}_{0}\right)$

where $\mathrm{P}_{1}(\mathrm{t})$ is the point heating power, and $\delta\left(\mathrm{x}-\mathrm{x}_{0}\right)$ is the Dirac delta function. It has a value of 1 at our desired location $\left(\mathrm{X}_{0}\right.$, $\mathrm{X}_{0}$ ) and 0 elsewhere. That's why it allows depositing total heating power at the tumor site. In this investigation, the force convection boundary condition is applied at the skin surface. Where $P_{1}(t)=2500 \mathrm{~W} / \mathrm{m}^{2}$, force convection coefficient $h_{f}=100$ $\mathrm{W} /\left(\mathrm{m}^{2}{ }^{\circ} \mathrm{C}\right)$ and $\mathrm{T}_{\mathrm{f}}=15^{\circ} \mathrm{C}$.

Figure 11a shows the temperature subjected to single heating source heating the point at $(15 \mathrm{~mm}, 15 \mathrm{~mm})$, where Figure 11b shows the result for two heating sources at $(10.5 \mathrm{~mm}, \quad 10.5 \mathrm{~mm})$ and $(20.5 \mathrm{~mm}, \quad 20.5 \mathrm{~mm})$. Thermal response of tissue subject to three heating sources at $(10.5 \mathrm{~mm}$, $10.5 \mathrm{~mm}),(10.5 \mathrm{~mm}, 20.5 \mathrm{~mm})$, and $(20.5 \mathrm{~mm}, 15 \mathrm{~mm})$ is depicted in Figure 11c. Here the maximum recorded temperature is $70^{\circ} \mathrm{C}, 75^{\circ} \mathrm{C}$, and $80^{\circ} \mathrm{C}$, respectively in Figure 11a, 11b, and 11c. Note that each figure showing the skin surface temperature below $30^{\circ} \mathrm{C}$. This scenario happens as cooling water is circulated over the skin surface.

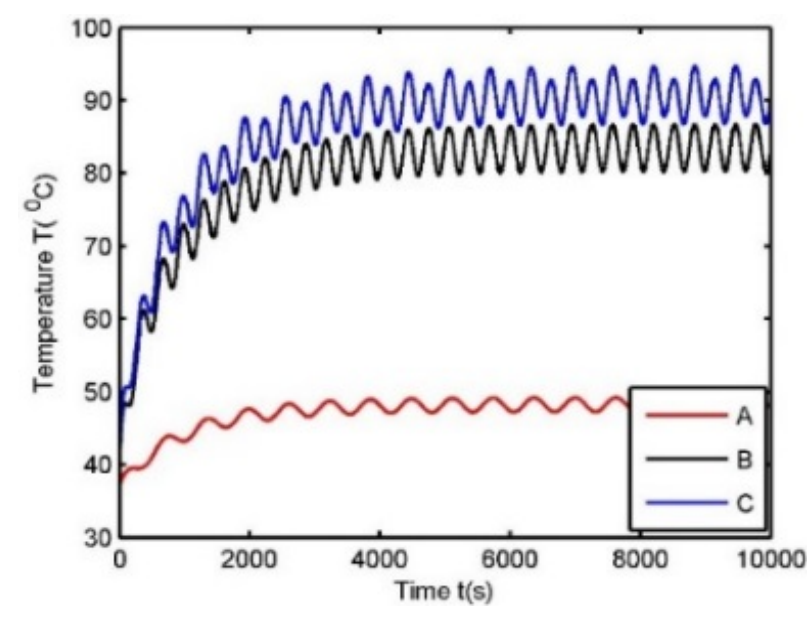

Figure 10. Effect of irregular heating frequency

(a)
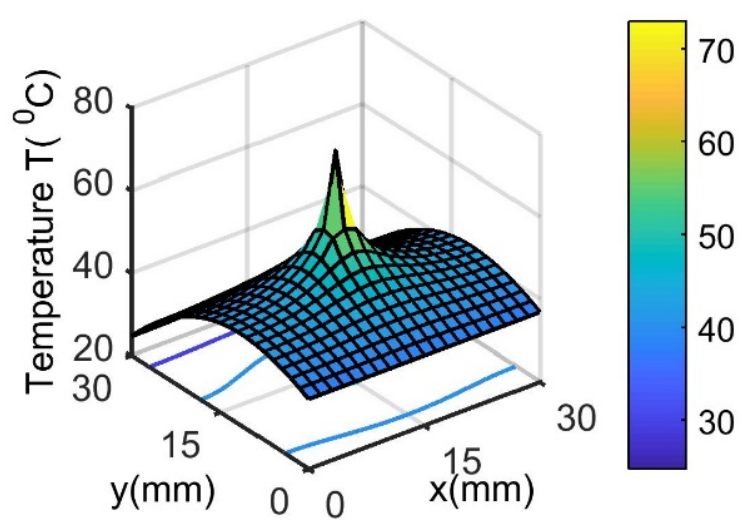

(b)

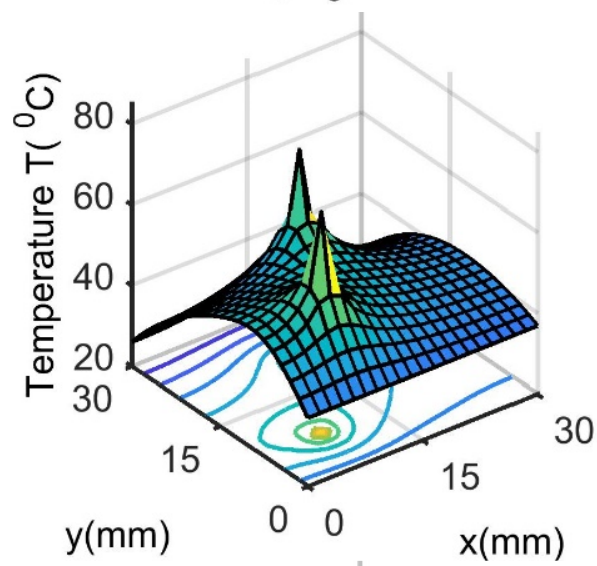

(c)

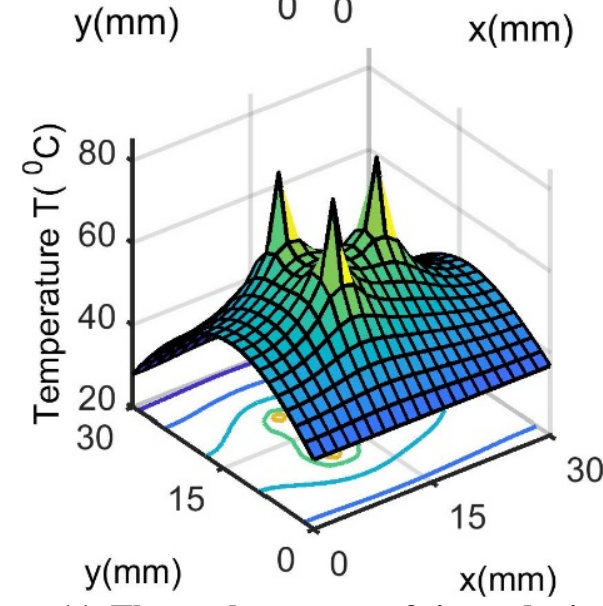

Figure 11. Thermal response of tissue during point heating 
However, applying three heat sources increase the temperature more rapidly and heated more region than using a single and double heat source. Multiple heat sources generate more heat through the tissue. So when the target region is quite larger it is beneficial to use multiple heat sources.

\subsection{Effect of Blood Temperature}

The arterial temperature, which is considered as constant, may be interrupted for many situations, i.e. for hypothermia or fever case. Thus, it is necessary to know its effect on the thermoregulation of biological tissues. Figure 12 shows the effect of arterial temperature for four sets of blood temperatures $34^{\circ} \mathrm{C}, 37^{\circ} \mathrm{C}, 39^{\circ} \mathrm{C}, 41^{\circ} \mathrm{C}$. The result shows that tissue temperature increases as the arterial temperature increases. This information can be beneficial for thermal diagnosis analysis. After getting the tissue temperature, it is possible to detect abnormality in the human body. For example, in this study, when the tissue temperature is $45.5^{\circ} \mathrm{C}$ it ensures that blood temperature is $41^{\circ} \mathrm{C}$, so it is the hyperthermia case. Moreover, in the case of hypothermia, the blood temperature is about $34^{\circ} \mathrm{C}$, which reduces the tissue temperature to almost $41.6^{\circ} \mathrm{C}$. Here, the natural convection boundary condition (Equation 11.1) is used as a skin surface boundary condition.

\subsection{Effect of Thermal Conductivity}

In our study, we have considered constant thermal conductivity. In practice, the tissue thermal conductivity is temperature-dependent. Moreover, in some cases, it changes from person to person and for the tissue contaminant. So, it is convenient to know the effect of such variation on the tissue temperature. To investigate the effect of thermal conductivity data values $0.25 \mathrm{~W} /\left(\mathrm{m} \cdot{ }^{\circ} \mathrm{C}\right), 0.50 \mathrm{~W} /\left(\mathrm{m} \cdot{ }^{\circ} \mathrm{C}\right)$ and $0.75 \mathrm{~W} /$ $\left(\mathrm{m} \cdot{ }^{\circ} \mathrm{C}\right)$ is used. Here natural convection boundary condition (Equation 11.1) is used as a skin surface boundary condition. Figure 13 shows the result. Three curves show the temperature distribution along with the $\mathrm{x}$-axis for three different values. Clearly, as the thermal conductivity increases tissue temperature decreases. It is because as thermal conductivity increases, much heat is transferred to the nearby tissue. But due to temperature boundary conditions at the body core, it further starts to decrease to keep the core temperature constant.

\subsection{Effect of Blood perfusion}

Another important parameter that plays a significant role in heat transport in human tissue is blood perfusion. In the human body, heat is carried away by the blood vessel. So a high blood flow rate results in reducing tissue temperature, conversely a lower blood flow rate increases the temperature. In this study blood perfusion is considered as constant. However, other researchers do not agree with such an assumption.

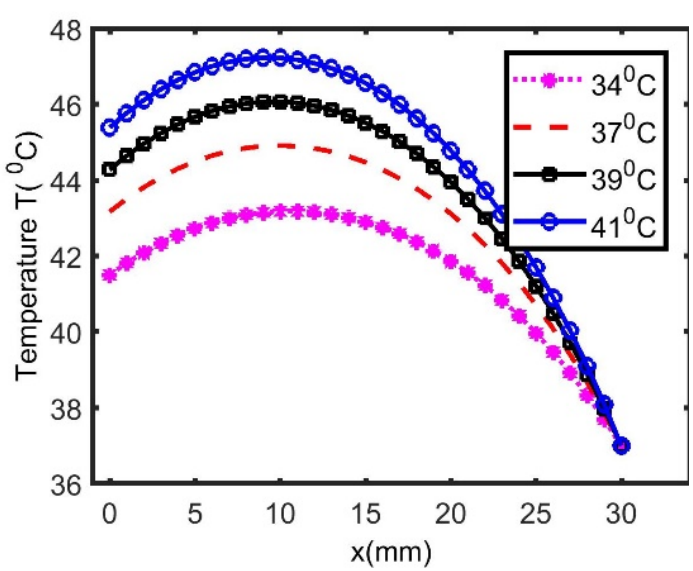

Figure 12. Effect of blood temperature

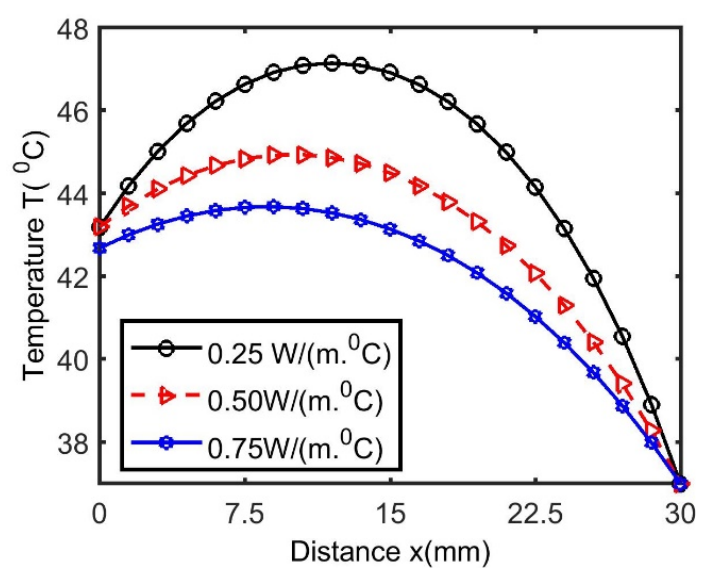

Figure 13. Effect of thermal conductivity

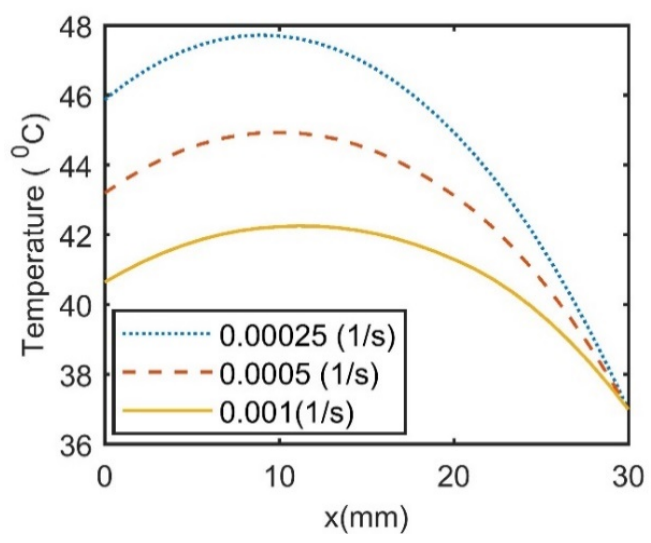

Figure 14. Effect of blood perfusion

Expression of blood perfusion as a temperature-dependent function is made in ${ }^{18}$ as $\omega=\omega_{0}+\gamma \mathrm{T}+\delta \mathrm{T}^{2}$ where $\omega_{0}$ is the base perfusion, $\gamma$ and $\delta$ are the linear and quadratic coefficients of temperature dependency. Moreover, in ${ }^{23}$ it was expressed as $\omega=\omega_{0}(1+\alpha \mathrm{T})$. Where $\omega_{0}$ is the base perfusion, $\alpha$ is a linear coefficient of temperature dependency. Where in some cases blood perfusion is expressed as a function of temperature and damage rate ${ }^{35}$.

To know the effect of blood perfusion data values 0.00025 $\mathrm{s}^{-1}, 0.0005 \mathrm{~s}^{-1}, 0.01 \mathrm{~s}^{-1}$ have been used for investigation. Besides, natural convection boundary condition (Equation 11.1) was used as a skin surface boundary condition. The result is shown in Figure 14. 
It is clear from this figure that higher blood perfusion results in lower temperatures. Conversely, a low blood perfusion rate leads to higher tissue temperature. However, the effect of temperature boundary condition bound the body core temperature to be constant $37^{\circ} \mathrm{C}$ for different blood perfusion rate. Another vital piece of information that can be drawn from this figure is that a slight change in blood perfusion rate results in a massive change in tissue temperature. So, we can say that blood perfusion plays a crucial role in human skin thermoregulation. So the accuracy of thermal modeling of human tissue greatly depends on the accurate prediction of blood perfusion rate.

\section{Conclusions}

This research presents the two-dimensional Finite Element Model based on Pennes bio-heat equation. The finite element system has been developed to measure the temperature of tissue for different heating conditions. Results are verified with the analytical and other numerical solutions available in the literature. Temperature distributions inside the human tissue subject to spatial heating, surface heating, and point heating are analyzed and briefly discussed. Spatial heating shifts the position of maximum temperature towards the body core.
Moreover, there is an exponential decay form of the temperature curve from the skin surface to the body core. Both the effect of constant and sinusoidal spatial heating is almost the same except for the presence of sinusoidal oscillation in sinusoidal spatial heating. Surface heating shows the same results. Surface heating mainly increases the temperature of the skin surface more rapidly. Its effect decreases towards the body core. The effect of heating frequency is related to the oscillation of the tissue temperature, but it keeps the mean temperature almost the same. The effect of irregular frequency remarkably influences the tissue temperature. However, its effect on the mean temperature is not significant enough. Point heating increases the temperature of the target region more rapidly with less effect on the nearby tissue. In this particular heating style, the temperature of the malignant tissue can be selectively controlled keeping the temperature of the healthy tissues below the injury threshold. That's why it is the most accepted method for treating deep tumors. The result found in this research shows that there is an effect of thermal conductivity of tissue and blood perfusion rate on the tissue temperature. This solution can also be used to determine the required temperature to kill the malignant cells as well as optimizing the treatment procedure.

\section{References}

1. Pennes HH. Analysis of tissue and arterial blood temperatures in the resting human forearm. Journal of Applied Physiology. 1948:1(2):93-122.

2. Scott JA. A finite element model of heat transport in the human eye. Physics in Medicine and Biology. 1988:33(2):227.

3. Ooi EH, Ang W-T, Ng EYK. Bioheat transfer in the human eye: a boundary element approach. Engineering Analysis with Boundary Elements. 2007;31(6):494-500.

4. Kenneth DR, Hayes LJ. Analysis of tissue injury by burning: comparison of in situ and skin flap models. International Journal of Heat and Mass Transfer. 1991:34(6):1393-1406.

5. Torvi DA, Dale JD. A finite element model of skin subjected to a flash fire. Journal of Biomechanical Engineering. 1994;116(3):250255.

6. Bagaria HG, Johnson DT. Transient solution to the bioheat equation and optimization for magnetic fluid hyperthermia treatment. International Journal of Hyperthermia. 2005;21(1):57-75.

7. Javidi M, Heydari M, Karimi A, et al. Evaluation of the effects of injection velocity and different gel concentrations on nanoparticles in hyperthermia therapy. Journal of Biomedical Physics \& Engineering. 2014;4(4):151-162.

8. Liu H-L, Chen Y-Y, Yen J-Y, Lin W-L. Thermal lesion formation and determination for external ultrasound thermal therapy. Biomedical Engineering: Applications, Basis and Communications. 2003;15(3):124-132.

9. Mizera A, Gambin B. Modelling of ultrasound therapeutic heating and numerical study of the dynamics of the induced heat shock response. Communications in Nonlinear Science and Numerical Simulation. 2011;16(5):2342-2349.

10. Sukru O, Helhel S, Cerezci O. Heat analysis of biological tissue exposed to microwave by using thermal wave model of bio-heat transfer (TWMBT). Burns. 2008;34(1):45-49.

11. Rabin Y, Shitzer A. Numerical solution of the multidimensional freezing problem during cryosurgery. Journal of Biomechanical Engineering. 1998;120(1):32-37.

12. Yeung CJ, Atalar E. A Green's function approach to local rf heating in interventional MRI. Medical Physics. 2001;28(5):826-832.

13. Supan, Tungjitkusolmun, Staelin ST, Haemmerich D, et al. Three-dimensional finite-element analyses for radio-frequency hepatic tumor ablation. IEEE Transactions on Biomedical Engineering. 2002;49(1):3-9.

14. Sturesson C, Andersson-Engels S. A mathematical model for predicting the temperature distribution in laser-induced hyperthermia. Experimental evaluation and applications. Physics in Medicine and Biology.1995:40(12):2037-2052. 
15. Whiting P, Dowden JM, Kapadia PD, Davis MP. A one-dimensional mathematical model of laser induced thermal ablation of biological tissue. Lasers in Medical Science. 1992:7:357-368.

16. Nyborg WL. Solutions of the bio-heat transfer equation. Physics in Medicine and Biology. 1988;33(7):785.

17. Deng Z_S, Liu J. Analytical study on bioheat transfer problems with spatial or transient heating on skin surface or inside biological bodies. Journal of Biomechanical Engineering. 2002;124(6):638-649.

18. Emmanuel K, Lakhssassi A, Vaillancourt R. Temperature distribution in living biological tissue simultaneously subjected to oscillatory surface and spatial heating: analytical and numerical analysis. International Mathematical Forum. 2012;7(48):2373-2392.

19. Liu K-C. Thermal propagation analysis for living tissue with surface heating. International Journal of Thermal Sciences. 2008;4(5):507-513.

20. Ahmadikia H, Fazlali R, Moradi A. Analytical solution of the parabolic and hyperbolic heat transfer equations with constant and transient heat flux conditions on skin tissue. International Communications in Heat and Mass Transfer. 2012;39(1):121-130.

21. Shih T-C, Yuan P, Lin W-L, Kou H-S. Analytical analysis of the Pennes bioheat transfer equation with sinusoidal heat flux condition on skin surface. Medical Engineering \& Physics. 2007;29(9):946-953.

22. Karaa S, Zhang J, Yang F. A numerical study of a 3D bioheat transfer problem with different spatial heating. Mathematics and Computers in Simulation. 2005;68(4):375-388.

23. Kengne E Mellal I, Hamouda MB, Lakhssassi A. A Mathematical Model to Solve Bio-Heat Transfer Problems through a Bio-Heat Transfer Equation with Quadratic Temperature-Dependent Blood Perfusion under a Constant Spatial Heating on Skin Surface. Journal of Biomedical Science and Engineering 2014;7(9):721.

24. Sharma PR, Ali S, Katiyar VK. Mathematical modeling of temperature distribution on skin surface and inside biological tissue with different heating. 13th International Conference on Biomedical Engineering. Springer, Berlin, Heidelberg, 2009.

25. Yuan P, Liu H-E, Chen C-W, Kou H-S. Temperature response in biological tissue by alternating heating and cooling modalities with sinusoidal temperature oscillation on the skin. International Communications in Heat and Mass Transfer. 2008;35(9):1091-1096.

26. Leilei C, Qin Q-H, Zhao N. An RBF-MFS model for analysing thermal behaviour of skin tissues. International Journal of Heat and Mass Transfer. 2010;53(7):1298-1307.

27. Deng Z-S, Liu J. Parametric studies on the phase shift method to measure the blood perfusion of biological bodies. Medical Engineering \& Physics. 2000;22(10):693-702.

28. Liu J, Xu LX. Estimation of blood perfusion using phase shift in temperature response to sinusoidal heating at the skin surface. IEEE Transactions on Biomedical Engineering. 1999;46(9):1037-1043.

29. Partridge PW, Wrobel LC. A coupled dual reciprocity BEM/genetic algorithm for identification of blood perfusion parameters. International Journal of Numerical Methods for Heat \& Fluid Flow. 2009;19(1):25-38.

30. Mukaddes AMM, Ogino M, Shioya R. Performance evaluation of domain decomposition method with sparse matrix storage schemes in modern supercomputer. International Journal of Computational Methods. 2014;11(supp01):1344007.

31. Mukaddes AMM, Shioya R, Masao O, et al. Finite Element Based Analysis of Bio-Heat Transfer in Human Skin During Burn and Afterwards. International Journal of Computational Methods. https://doi.org/10.1142/S0219876220410108

32. Holmes KR. Biological structures and heat transfer. Allerton Workshop on the Future of Biothermal Engineering. 1997.

33. Carslaw HS, Jaeger JC. Conduction of heat in solids. Oxford: Clarendon Press, 1959, 2nd ed. (1959).

34. Leonard JB, Foster KR, Athley TW. Thermal properties of tissue equivalent phantom materials. IEEE Transactions on Biomedical Engineering. 1984;31(7):533-536.

35. London RA, Glinsky ME, Zimmerman GB, et al. Laser-Tissue Interaction Modeling With LATIS. Applied Optics. 1997;36(34):9068-9074.

36. Deng Z-S, Liu J. Monte Carlo method to solve multidimensional bioheat transfer problem. Numerical Heat Transfer: Part B: Fundamental. 2002;42(6):543-567.

37. Habash R, Bansal R, Krewski D, et al. Thermal therapy, part 1: an introduction to thermal therapy. Critical Reviews in Biomedical Engineering. 2006;34(6):459-489.

38. Habash R, Bansal R, Krewski D, et al. Thermal therapy, part 2: hyperthermia techniques. Critical Reviews in Biomedical Engineering. 2006;34(6):491-542.

39. Habash R, Bansal R, Krewski D, et al. Thermal therapy, Part III: ablation techniques. Critical Reviews in Biomedical Engineering. 2007;35(1-2):37-121.

40. Xiaoming H, Bischof JC. Quantification of temperature and injury response in thermal therapy and cryosurgery. Critical Reviews in Biomedical Engineering. 2003;31(5-6):355-422.

41. Liu J, Xu LX. Boundary information based diagnostics on the thermal states of biological bodies. International Journal of Heat and Mass Transfer. 2000;43(16):2827-2839. 
42. Ma N, Gao X, Zhang XX. Two-Layer Simulation Model of Laser-Induced Interstitial Thermo-Therapy. Lasers in Medical Science. 2004;18:184-189.

43. Scott JA. The computation of temperature rises in the human eye induced by infrared radiation. Physics in Medicine and Biology. 1988:33(2):243-257. 